\title{
The molecular basis of genetic dominance
}

\author{
Andrew O M Wilkie
}

\begin{abstract}
Studies of mutagenesis in many organisms indicate that the majority (over $90 \%$ ) of mutations are recessive to wild type. If recessiveness represents the 'default' state, what are the distinguishing features that make a minority of mutations give rise to dominant or semidominant characters? This review draws on the rapid expansion in knowledge of molecular and cellular biology to classify the molecular mechanisms of dominant mutation. The categories discussed include (1) reduced gene dosage, expression, or protein activity (haploinsufficiency); (2) increased gene dosage; (3) ectopic or temporally altered mRNA expression; (4) increased or constitutive protein activity; (5) dominant negative effects; (6) altered structural proteins; (7) toxic protein alterations; and (8) new protein functions. This provides a framework for understanding the basis of dominant genetic phenomena in humans and other organisms.
\end{abstract}

\section{(f Med Genet 1994;31:89-98)}

The concepts of dominance and recessiveness (or recessivity), originally formulated by Mendel, ${ }^{1}$ are so fundamental to genetics that they are often taken for granted. But why are some diseases dominant and others recessive? This question is frequently ignored in textbooks of genetics, and it is surprisingly difficult to find much written on the subject. With the rapid accumulation of molecular data on diploid organisms as diverse as yeasts and humans, unifying themes are beginning to emerge. This review attempts to classify and elaborate these ideas, and collates some of the more useful references. I will first outline some definitions and concepts, and then give illustrative examples of different molecular mechanisms of dominance. Although I have focused on human disorders where possible, many additional lessons can be learned from the study of non-human systems.

Genetics, University Hospital of Wales, Heath Park, Cardiff CF4 4XW, UK A O M Wilkie

Correspondence to Dr Wilkie, Institute of Molecular Medicine, John Molecular Medicine, Headington, Oxford OX 3 Headington,
9DU, UK.
It should first be remembered that dominance is not an intrinsic property of a gene or mutant allele, but describes the relationship between the phenotypes of three genotypes: an allele may behave as a dominant, semidominant, or recessive depending both on its partner allele, and the character under consideration. ${ }^{3}$ Consider alleles $\mathrm{A}$ and $\mathrm{B}$, with genotypes $\mathrm{AA}, \mathrm{AB}$, and $B B$. If a particular phenotypic character is observed in the $\mathrm{AA}$ and $\mathrm{AB}$ genotypes, but differs from $B B$, then allele $A$ is dominant to allele $B$. When the $A B$ phenotype is intermediate between or combines characters from both the $\mathrm{AA}$ and $\mathrm{BB}$ phenotypes, alleles $\mathrm{A}$ and $B$ are semi- or codominant. Most wild type alleles are dominant over other alleles, as the wild type and heterozygote phenotypes are usually indistinguishable; thus most genetic diseases are recessive (fig 1 ).

A potential source of confusion when considering dominance phenomena in human genetic disease, is that only the wild type and heterozygous mutant phenotypes are generally encountered. Examples of homozygous mutants both for relatively common disorders (thalassaemia, familial hypercholesterolaemia) and rarer conditions (achondroplasia, piebaldism) indicate that the phenotype of the homozygote usually tends to be more severe than the heterozygote, hence the wild type and mutant alleles are, strictly speaking, semidominant. $^{4-6}$ The Huntington's disease mutation provides an unusual instance of a mutant allele that is truly dominant to wild type in that homozygotes appear no more severely affected than heterozygotes ${ }^{7-9}$ (fig 1). Although it is interesting to speculate on the differences in mechanism giving rise to semidominance and complete dominance, there are insufficient molecular data to attempt a synthesis. The more simple, but perhaps more fundamental, question addressed in this review may be summarised as follows: what aspects of a mutant allele's function cause it to affect the phenotype in the presence of a wild type allele? For simplicity I will use the term 'dominant mutation' to describe a mutant allele in this context.

\section{Dominant mutations are much rarer than recessive ones}

Although dominant disorders outnumber recessives by a ratio of nearly 4:1 in McKusick's 1992 compilation, ${ }^{10}$ ascertainment in the human is undoubtedly biased in favour of mild dominantly inherited phenotypes. By contrast, it has long been known from systematic mutagenesis of a variety of diploid organisms that the majority of mutations are recessive to wild 


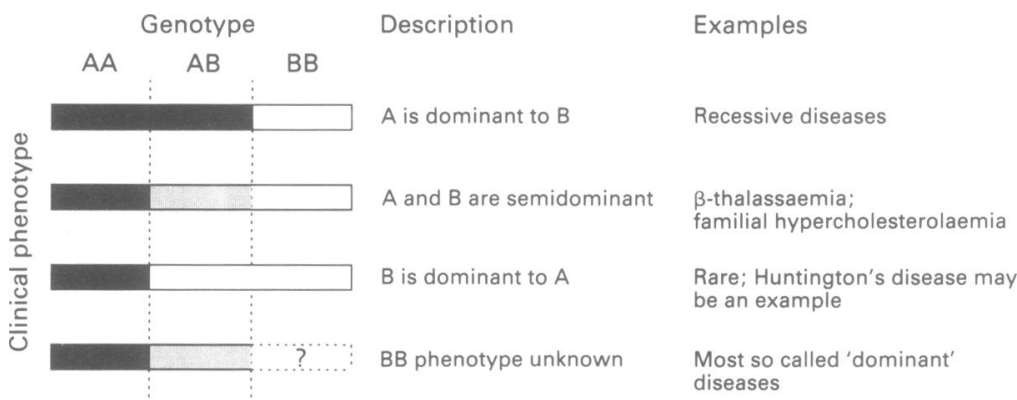

Figure 1 Relationship between genotype and clinical phenotype. $A$ is a wild type allele and $B$ a mutant allele; different phenotypes are represented by different shaded blocks.

type. ${ }^{11}$ For example, insertional inactivation by random integration of retroviral DNA into the mouse genome produces recessive and dominant phenotypes with a ratio of about 10$20: 1.1213$

The search for an explanation of the recessive behaviour of most mutations generated a lively debate in the 1930s between Sewall Wright, who believed that it arose intrinsically from the physiology of gene action, and RA Fisher, who proposed that the accumulation of modifier alleles at other loci was responsible. Fisher's theory has now generally lost favour, and $\mathrm{Orr}^{14}$ showed that in the alga Chlamydomonas, which is usually haploid (so that Fisherian selection cannot apply), most mutations nevertheless showed recessive behaviour when examined in a transiently diploid background, supporting Wright's theory. Indeed, diploidy may have evolved because it protects against recessive mutations. ${ }^{15-17}$ Thus it is dominance, rather than recessiveness, that demands special explanation; but why should the 'default' state of mutations be recessive?

The usual explanation is as follows. The most likely effects of a random gene mutation are that it will either be neutral (normal phenotype) or inactivating. If the latter, the question is whether the inactivation would be clinically manifest in the heterozygote (dominance or semidominance, specifically, haploinsuffi-

Molecular classification

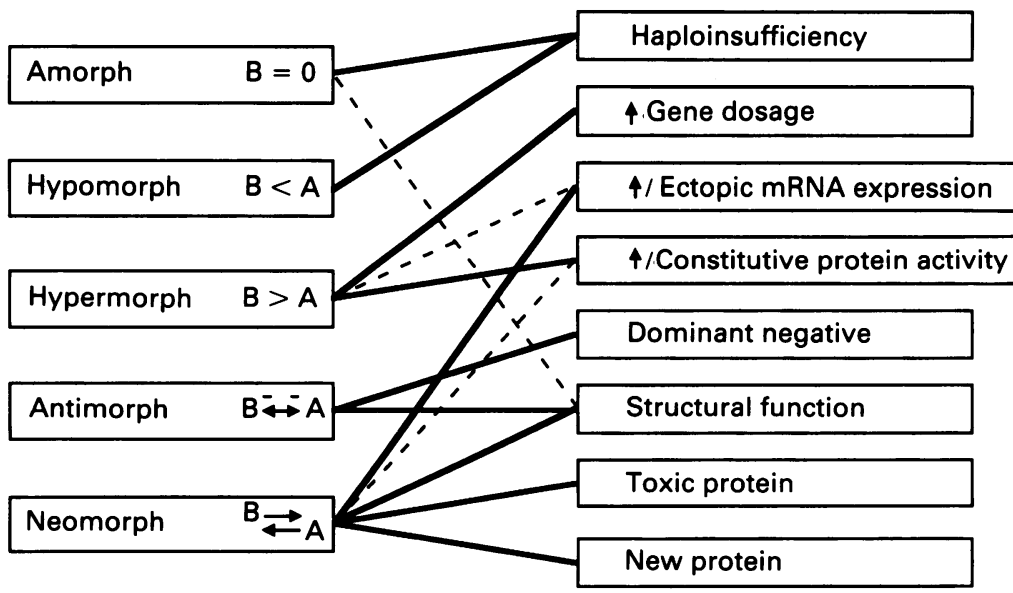

Figure 2 Relationship between genetic and molecular mechanisms of dominance. The genetic classification is that formulated by Muller $^{23}$; the relationship between wild type $(A)$ and mutant $(B)$ alleles is indicated diagrammatically. Thick lines join categories that commonly show equivalence; dashed lines connect less frequent groupings. ciency), or only in the homozygote (recessiveness). In 1981 Kacser and Burns ${ }^{18}$ proposed a theory of metabolic fluxes to explain why most inborn errors of metabolism are recessive. Assuming that a metabolic pathway has many non-rate limiting steps, control of flux at any particular point in a pathway will be small. Hence, many pathways show a saturable relationship between enzyme level and metabolic flux, with fluxes fully saturated at wild type enzyme level; a $50 \%$ reduction in enzyme activity would therefore cause little reduction in flux below its saturation level.

Although this theory fits metabolic pathways well, it is not applicable to critical rate limiting steps of such pathways, nor to mutations causing qualitatively altered function, especially when structural or controlling/signalling proteins are involved. It is perhaps not surprising that most dominant mutants belong to one of these latter categories, and frequently involve developmental malformations.

An additional explanation for the rarity of dominant mutations is suggested by work on the nematode Caenorhabditis elegans. Recessive mutations at a series of loci termed smg may alter the behaviour of mutations at other loci from recessive to dominant (cryptic dominance). It seems that the wild type smg loci encode proteins that can recognise and selectively degrade many mutant mRNA species, forming part of a mutant surveillance system. ${ }^{1920}$ The relevance of this finding to humans is not yet clear.

Finally, note that although the number of known recessive conditions in the human may considerably underestimate the total, the true figure is unlikely to approach the total number of genes. There is a growing list of murine genes for which targeted disruption is not associated with any phenotypic abnormality in transgenic mice..$^{21} \mathrm{~A}$ similar situation applies to the mutational spectrum in $C$ elegans, and it is noteworthy that dominant "gain of function" mutants exist at several loci for which the homozygous null phenotype is entirely nor$\mathrm{mal}^{22}$

\section{Types of dominant mutation}

In 1932, Muller ${ }^{23}$ suggested a classification of dominant mutations that is still widely quoted. He coined the terms amorph, hypomorph, and hypermorph to reflect quantitative changes to a pre-existing wild type character; antimorph to describe mutual antagonistic interaction with wild type; and neomorph for a new phenotype, not fully antagonised by wild type. His proposal, made when the molecular nature of mutation was still uncertain (and predating the identification of DNA as the genetic material by 12 years), ${ }^{24}$ was remarkable for its prescience. Unfortunately, later authors have sometimes tended to assume a one to one relationship between this classification, based on classical genetics, and underlying molecular mechanism. While clear parallels exist, these are inexact (fig 2). As this review focuses on molecular mechanisms of dominance, I have avoided using Muller's terms to highlight the 
distinction between the genetic and molecular levels of analysis. The following classification seems to accommodate most situations, although some ambiguities and overlaps are inevitable.

(1) Reduced gene dosage, expression, or protein activity: haploinsufficiency.

(2) Increased gene dosage.

(3) Ectopic or temporally altered mRNA expression.

(4) Increased or constitutive protein activity.

(5) Dominant negative effects.

(6) Altered structural proteins.

(7) Toxic protein alterations, not covered in other categories.

(8) New protein functions.

Some examples of these mechanisms are shown in the table and are further discussed below. A general distinction can be made between category (1), which involves loss of function, and categories (2) to (8), which represent gain of function. Note that the latter, frequently used term encompasses a wide range of mechanisms, and is thus only applicable in a broad context. The table includes two other mechanisms that may give rise to a "dominant" pattern of inheritance, but in which the inherited mutation is not dominant at a cellular level. These involve recessive antioncogenes and genomic imprinting, and are discussed briefly in a later section.

REDUCED GENE DOSAGE, EXPRESSION, OR PROTEIN ACTIVITY: HAPLOINSUFFICIENCY For the minority of cases in which the abnormal phenotype results from inactivation of one of a pair of alleles, the term "haploinsufficiency" is used ("haplolethality" if early embryonic death occurs). Haploinsufficient loci are relatively unusual: a careful survey of the Drosophila genome showed only 56 loci associated with an altered phenotype when present as a single copy, of which four were lethal. ${ }^{25}$ However, such loci are more import- ant than their rarity might suggest, for two reasons. First, mutation may arise from any mechanism producing loss of function: deletion, chromosome translocation, truncation caused by nonsense and frameshift mutation, and some promoter and splice site mutations and amino acid substitutions may all be responsible. Such variety will tend to increase the frequency with which the disease is observed. Second, dosage sensitive genes seem to be an intrinsically interesting group. ${ }^{26}$

Genes showing haploinsufficiency fall into two broad categories. A few code for tissue specific proteins synthesised in large quantities, for instance, type 1 collagen $^{27}$ (but see also the section on structural mutations), globins, low density lipoprotein receptor, ${ }^{28}$ haem synthesis (porphyrias), ${ }^{2}$ and $\mathrm{Cl}$ esterase inhibitor (hereditary angio-oedema). ${ }^{29}$ In the first two cases, the abnormal heterozygous phenotype may be because of the resulting imbalance with a matched component protein; in the latter three, because of interference with a rate limiting step of a metabolic pathway. Of particular note, levels of $\mathrm{Cl}$ esterase inhibitor associated with heterozygous deficiency are only 15 to $20 \%$ of normal, even during remission. This is because the normal inhibitor is "mopped up" relatively rapidly by complexing with plasma enzymes, and the rate at which this occurs is largely independent of inhibitor concentration (zero order kinetics). ${ }^{29}$ The quantitative deficiency is hence greater than the expected value of $50 \%$.

A second category comprises regulatory genes working close to a threshold level for different actions. Examples in humans include PAX3 (Waardenburg syndrome), ${ }^{30} 31$ PAX6 (aniridia), ${ }^{32}$ GLI3 (Greig cephalopolysyndactyly, GCPS), ${ }^{334}$ WT1 (Wilms's tumour/genitourinary abnormalities), ${ }^{35} 36$ RDS/peripherin (retinitis pigmentosa), ${ }^{37}$ and KIT (piebaldism). ${ }^{38}$ Such threshold dosage effects may be clinically manifest in only a subset of the tissues in which the gene is expressed (aniridia

Major categories and mechanisms of genetic dominance, with the types of mutation commonly responsible. See text for further examples and references. $D=$ large deletion, $T=$ truncation (nonsense or frameshift mutation), $M=$ missense mutation or small in frame deletion, $S=$ splice site mutation, $P=$ promoter mutation, Tr $=$ translocation or other rearrangement, Dup $=$ duplication, $A=$ amplification, ()$=$ inconsistent association.

\begin{tabular}{|c|c|c|c|}
\hline Category of mutation & Mechanism & Types of mutation & Examples \\
\hline $\begin{array}{l}\text { Loss of function } \\
\text { Haploinsufficiency }\end{array}$ & $\begin{array}{l}\text { Subunit imbalance } \\
\text { Metabolic rate determining step } \\
\text { Developmental regulator }\end{array}$ & $\begin{array}{l}\text { D, T, S, (M) } \\
\text { D, T, S, }(M) \\
\text { D. T, S, (M), (Tr) }\end{array}$ & $\begin{array}{l}\alpha \text { and } \beta \text { globins } \\
\text { LDL receptor } \\
\text { PAX3, PAX6 }\end{array}$ \\
\hline $\begin{array}{l}\text { Gain of function } \\
\uparrow \text { Gene dosage }\end{array}$ & $\begin{array}{l}\text { Duplication } \\
\text { Amplification }\end{array}$ & $\begin{array}{l}\text { Dup } \\
\text { A }\end{array}$ & $\begin{array}{l}\text { PMP-22 } \\
\text { MDM2 }\end{array}$ \\
\hline$\uparrow /$ Ectopic mRNA expression & $\begin{array}{l}\text { Altered temporal pattern } \\
\text { Altered tissue distribution } \\
\uparrow \text { mRNA stability }\end{array}$ & $\begin{array}{l}\text { P,Tr,(D) } \\
\text { P, Tr } \\
\text { D }\end{array}$ & $\begin{array}{l}\gamma \text { globin, MYC } \\
\text { Ubx, Antp, MYC } \\
\text { lin-14 }\end{array}$ \\
\hline $\begin{array}{l}\uparrow / \text { Constitutive protein } \\
\text { activity }\end{array}$ & $\begin{array}{l}\uparrow \text { Stability (PEST deletion) } \\
\text { Constitutive activation }\end{array}$ & $\begin{array}{l}\mathrm{T} \\
\mathrm{M}\end{array}$ & $\begin{array}{l}\text { CLN3, glp-1 } \\
\text { RAS, Gs } \alpha, \text { SCN } 4 \text { A }\end{array}$ \\
\hline Dominant negative & $\begin{array}{l}\text { Disruption of dimer } \\
\text { Competition for substrate }\end{array}$ & $\begin{array}{l}M,(T) \\
M,(T)\end{array}$ & $\begin{array}{l}\text { KIT, p53 } \\
\text { RAS }\end{array}$ \\
\hline Structural protein & Disruption of structure & $M, S,(T)$ & Collagen, fibrillin \\
\hline Toxic protein & Disruptive interaction & $\mathbf{M}$ & Rhodopsin, amyloidoses \\
\hline $\begin{array}{l}\text { New protein } \\
\text { Other mechanisms }\end{array}$ & $\begin{array}{l}\text { Altered substrate specificity } \\
\text { Exon shuffling }\end{array}$ & $\begin{array}{l}M \\
\operatorname{Tr}\end{array}$ & $\begin{array}{l}\boldsymbol{x}_{1} \text { antitrypsin } \\
\text { BCR/ABL }\end{array}$ \\
\hline & $\begin{array}{l}\text { Recessive antioncogene } \\
\text { Genomic imprinting }\end{array}$ & $\overline{-}$ & $\begin{array}{l}\text { Retinoblastoma } \\
\text { Beckwith-Wiedemann syndrome }\end{array}$ \\
\hline
\end{tabular}


and GCPS are examples) and the phenotype may be sensitive to the genetic background.

To understand the mechanisms of dosage sensitivity in this "regulatory" group requires a detailed knowledge of the molecular interactions involved, something not yet achieved for any human gene. However, simpler organisms provide some excellent model systems. For instance, sex determination in Drosophila requires the ability to distinguish between X:autosomal ratios of 1 in females and 0.5 in males. This may be achieved by titration of "numerator" $\mathrm{X}$ chromosome genes against "denominator" autosomal ones, possibly by competition of the cognate proteins for binding to a regulatory DNA sequence. ${ }^{39}$ Further insight may be gained by studies of morphogenic proteins, for example the Drosophila transcription factor dorsal ( $\mathrm{dl})$, which is distributed in a nuclear concentration gradient along the dorsoventral axis of the early embryo. Dosage dependent activation of different sets of downstream genes by dl correlates with the strength of the dl binding sites in their promoters: genes with high affinity $\mathrm{dl}$ binding are activated or repressed by $\mathrm{dl}$ at lower threshold levels. ${ }^{4041}$ Correspondingly, female flies heterozygous for dl null mutations produce abnormal embryos that fail to develop mesoderm, which requires the highest level of dl activity. ${ }^{42}$

\section{INCREASED GENE DOSAGE}

Application of Kacser and Burns' principles ${ }^{18}$ predicts that an increase in gene dosage to three copies should affect the phenotype even less often than a reduction to one copy. Experimental analysis supports this: for example, the survey of aneuploidy in Drosophila previously mentioned $^{25}$ identified only one triplo-lethal and one triplo-abnormal locus. Nevertheless, cytogenetically visible trisomy in humans (which will usually encompass at least 40 to 50 genes) is usually associated with phenotypic abnormality, indicating that a significant minority of loci must be sensitive to 3 versus 2 dosage. It may be relevant that the increase in dosage at the mRNA and protein level can exceed the expected factor of 1.5; considerably greater rises are observed for some genes on chromosome 21 in Down's syndrome. ${ }^{43}$ Although the distinctive phenotypes associated with certain trisomies may therefore be attributable to a small number of critical genes, few of these have been specifically identified. An exception is PMP-22, duplication of which is likely to be the principal cause of type I Charcot-Marie-Tooth disease. ${ }^{4}$ The PMP-22 region is also haploinsufficient, giving the different phenotype of dominant pressure palsies ${ }^{45}$; however, the cellular mechanisms of these contrasting dosage effects are not understood.

Gene amplification in somatic cells to much higher copy numbers frequently occurs in certain neoplasias. ${ }^{46} \mathrm{~A}$ particularly clear example of how this causes a dominant phenotype is provided by the amplification of the MDM2 gene in sarcomas. MDM2 protein binds to and inactivates the tumour suppressor gene P53 (discussed further below), leading to escape from normal p53 regulated cellular growth control. ${ }^{47}$

\section{ECTOPIC OR TEMPORALLY ALTERED MRNA}

\section{EXPRESSION}

This group is characterised by disturbance of the exquisite controls of mRNA expression that dictate the normal cellular distribution, temporal restriction, and absolute levels of mRNA. In principle, altered gene expression can arise in any gene or message that contains a regulatory domain, and the molecular pathology of such mutants is correspondingly diverse. ${ }^{48}$

A fairly specific illustration of loss of temporal regulation is provided by hereditary persistence of fetal haemoglobin (HPFH). Known causes include point mutation of the $\gamma$ globin promoter, which alters binding of the erythroid transcription factor GATA-1, ${ }^{49}$ certain $3^{\prime}$ deletions encompassing the $\delta$ and $\beta$ globin genes, ${ }^{50}$ and alterations of unidentified trans acting factors. The effect of all these mutations is to abrogate the normal switch from expression of $\gamma$ to $\delta$ and $\beta$ globin, which occurs around the time of birth. The resulting HPFH dominantly ameliorates the effects of $\beta$ thalassaemia mutations.

An example of ectopic expression is provided by the contrabithorax (Cbx) mutations of Drosophila, which involve the ultrabithorax (Ubx) gene, normally expressed in the posterior part of the embryo with an anterior boundary in the third thoracic segment (T3). In Cbx mutants, which comprise insertions, inversions, and other chromosomal rearrangements, ${ }^{51} \mathrm{Ubx}$ is also expressed in T2 and this results in the homeotic transformation of T2 into a T3 like structure. Similarly, dominant homeotic mutations of the Antennapedia gene occur because of ectopic expression: in one case studied in detail (Antp ${ }^{73 b}$ ), a chromosomal inversion results in the entire Antp coding region being placed under a new promoter. ${ }^{52}$

More commonly, the disease phenotype may reflect a combination of alterations in the temporal specificity, tissue distribution, and absolute level of mRNA expression. The primary abnormality usually lies at the level of transcription, but sometimes mRNA processing may be affected. Examples of transcriptional alterations include the following. Chromosomal translocations resulting from errors in recombinase mediated gene rearrangement in lymphoid cells activate expression of transcription factors like MYC, causing B and T cell neoplasms. ${ }^{5354}$ Promoter mutations in the Caenorhabditis sex determining gene her-1 (the only member of this pathway subject to transcriptional control) increase expression levels and result in partial transformation of $\mathrm{XX}$ worms into phenotypic males. ${ }^{55}$ Increased, ectopic expression of a chimeric mRNA encoding a normal protein accounts for the lethal yellow mutant at the mouse agouti locus. ${ }^{5657}$

Control of expression at the level of mRNA 
processing is illustrated by the heterochronic (defining developmental time) $C$ elegans gene lin-14. Dominant mutants, which cause the reexpression of early cell lineages at later developmental stages, delete the $3^{\prime}$ untranslated region (UTR) of the mRNA and lead to raised protein levels. This $3^{\prime} \mathrm{UTR}$ may regulate export of the transcript from the nucleus, transcript stability, or translation. ${ }^{48}$ Splice site mutations of mRNA subject to differential splicing will alter the pattern of mature mRNA isoforms: this is observed at the WT1 locus. ${ }^{35} 5859$

INCREASED OR CONSTITUTIVE PROTEIN ACTIVITY At the protein level, increased activity may be caused by increased half life or by loss of normal inhibitory regulation (constitutive activity). One class of mutations conferring increased half life are those occurring in PEST sequences (rich in proline, glutamic acid, serine, and threonine), ${ }^{60}$ which act as recognition signals for proteolytic degradation: loss of these sequences by C-terminal truncation stabilises the protein. Examples of PEST deletions include mutations of the CLN3 gene of Schizosaccharomyces pombe (WHI-1/DAF-1 cell cycle mutants ${ }^{61}$ and the glp-1 gene of $C$ elegans. ${ }^{62}$ glp-1 is required for induction of germline proliferation and embryogenesis, and the glp-1(q35) point mutation is particularly instructive, as it causes both semidominant (multivulva) and recessive (sterility/embryonic

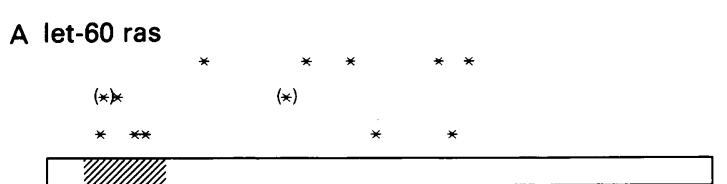

GTP/GDP binding

B Toll

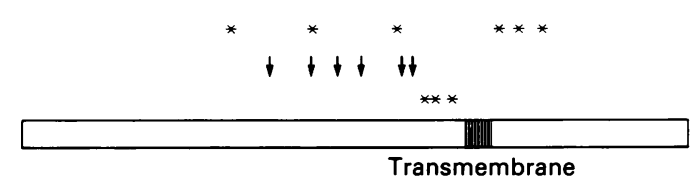

Recessive

'Class II' dominant Constitutive activation

C KIT

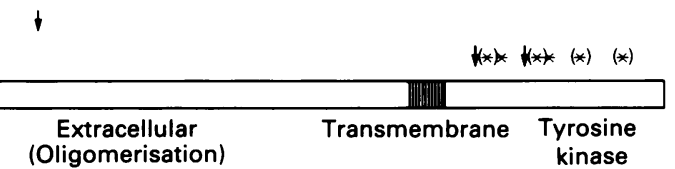

D P53

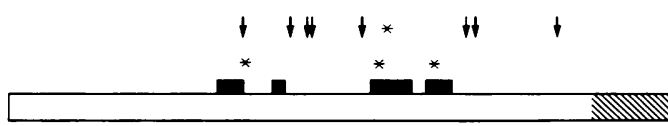

Mutational hotspots

Oligomerisation

Figure 3 Diagrammatic representation of four gene products, illustrating the complex relationship of point mutation to phenotype. The N-terminus is on the left. ${ }^{*}$ indicates a missense alteration, $\downarrow$ a frameshift or nonsense mutation leading to truncation. $(A)$ let -60 ras. ${ }^{6465}$ Additional mutations documented in human tumours ${ }^{63}$ are denoted (*). (B) Toll. ${ }^{66}$ (C) KIT $^{38}$ Truncations of the tyrosine kinase domain may have mixed haploinsufficient and dominant negative effects. Murine $W$ mutations ${ }^{3}$ are shown in brackets. (D) P53.67-69 Clusters of missense mutations are represented by black boxes. Four specific missense mutations tested in vitro for presence or absence of dominant negative effects ${ }^{69}$ are shown individually. lethality) phenotypes. The former is attributable to stabilisation of the truncated protein owing to the PEST deletion, while the latter may result from counteracting destabilisation of the mutant mRNA. ${ }^{62}$

A paradigmatic example of constitutive protein activation is provided by the RAS genes: oncogenic point mutations prevent GTP hydrolysis, thus maintaining the protein in an activated state ${ }^{63-65}$ (fig 3A). Similarly, activating missense mutations at the $201 \mathrm{Arg}$ residue of the $G_{s} \alpha$ protein (which stimulates adenylyl cyclase) have been documented (as somatic mosaics) in five cases of McCune-Albright syndrome. ${ }^{7071}$ Different point mutations in the adult skeletal muscle sodium channel $\alpha$ subunit gene SCN4A cause hyperkalaemic periodic paralysis ${ }^{7273}$ and paramyotonia congenita, ${ }^{74}$ by interfering with normal voltage sensitive inactivation of the sodium current. In view of the differing effects of single and triple dosage of the PMP-22 gene described above, it is interesting that the phenotype associated with a heterozygous missense mutation (16Leu $\rightarrow$ Pro) resembles that of triple dosage, that is, Charcot-Marie-Tooth disease..$^{75}$ This suggests that the missense mutation may increase PMP22 activity, but this has not yet been shown.

A particularly complex spectrum of mutations is encountered at the Drosophila locus Notch, which encodes a transmembrane receptor protein that transduces a variety of cellular signals, and includes an extracellular domain rich in epidermal growth factor (EGF) like repeats. Increased intrinsic activity is associated with some of the so called Abruptex mutations: these are missense, clustered in the EGF domain, and are thought to perturb the normal balance of homo- and heterodimeric protein interactions. ${ }^{7677}$ Heterozygous null (loss of function) mutations of Notch give a different phenotype, and yet other mutants exist that have recessive or dominant negative effects $^{7677}$ (see below). Another interesting Drosophila locus is Toll. This encodes a transmembrane protein that provides an unusual example of two distinct activation mechanisms (fig 3B). ${ }^{66}$ "Class I" mutants are missense and act constitutively, possibly owing to direct structural modulation of the protein. "Class II" mutants are truncations that retain the extracellular component: this activates wild type Toll by an undefined mechanism. Mutants in the class II group differ genetically from other categories of active protein mutants in that they are non-functional when heterozygous to a null. ${ }^{66}$ Such truncation mutants more commonly cause dominant negative effects, as described below.

\section{DOMINANT NEGATIVE MUTATIONS}

In the heterozygous state these mutants antagonise the activity of the remaining wild type allele, giving a phenotype approaching a null; when homozygous, or heterozygous to a null mutation, they are non-functional. Hersko$w_{i t z}{ }^{78}$ drew attention to the value of these mutations in experimental studies and proposed a classification. The major group com- 
prises multimeric proteins dependent on oligomerisation for activity: the presence in a multimer of a mutant subunit with intact binding but altered catalytic domains can abrogate the function of the entire multimer. For example, if the protein normally dimerises, admixture of equal numbers of normal and mutant subunits will result in only $25 \%$ normal dimers, potentially causing a $75 \%$ reduction in activity. For monomeric proteins, dominant negative mutations could occur if substrate was limiting: a mutant able to bind the substrate, but not metabolise it, would have this effect. Mutations of polymeric structural proteins, sometimes classed as dominant negative, are discussed separately (next section).

Dominant negative effects have been described in many types of protein with signalling or transcriptional functions. A specific example is provided by the DNA binding activity of Drosophila dorsal, mentioned previously, which depends on dimerisation: most mutations are true recessives, but one particular mutant exerts a dominant negative effect. This is an Arg $\rightarrow$ Cys substitution that maps to the DNA binding domain but does not affect oligomerisation: it appears to act by abolishing the DNA binding of normal/mutant heterodimers. ${ }^{40}$ Similarly the more severe phenotype associated with WT1 mutations in DenysDrash syndrome, as compared with Wilms's tumour/genitourinary abnormalities, may be explained by the dominant negative behaviour of specific zinc finger mutations in the former condition: it is not yet certain whether this is mediated by WT1 dimers. ${ }^{3536}$ Specific Abruptex missense mutations at the Drosophila Notch locus are dominant negative, as mentioned above. ${ }^{7677}$

A wider variety of mutations may cause dominant negative effects in the KIT protooncogene, manifested as white spotting (W) in the mouse and piebaldism in the human. KIT encodes a receptor tyrosine kinase and dimerisation, which occurs in response to ligand binding, is essential for activity. Whereas the piebald phenotype associated with complete KIT deletion is relatively mild in the heterozygote (haploinsufficiency), point mutations involving the intracellular tyrosine kinase domain cause severe disease ${ }^{338}$ (fig 3C). Truncations in the same domain tend to have a variable, intermediate phenotype: although partly the result of haploinsufficiency, a dominant negative effect is probably also contributing, as seen in an analogous truncation of the fibroblast growth factor receptor (FGF-R). ${ }^{79}$ The reovirus cell attachment protein provides a further example. ${ }^{80}$

Dominant negative effects may be very important in neoplasia, a paradigm being the tumour suppressor P53: a wide variety of acquired mutations has been described, the many missense mutants being concentrated in four clusters ${ }^{6768}$ (fig 3D). p53 oligomerises in vitro and can adopt two conformations, one active and the other inactive; wild type protein is normally in the active state. Cotranslation with certain missense mutants results in mixed oligomers that adopt the inactive conforma- tion. ${ }^{69}$ Thus, although P53 is conventionally viewed as a "recessive" tumour suppressor gene, some mutants can deregulate p53 function in a dominant negative fashion. In contrast, no alteration in wild type activity is induced by a missense mutant associated with the Li-Fraumeni syndrome, suggesting that Li-Fraumeni p53 mutants may be relatively "weak" ones. ${ }^{69}$ Note that the $\mathrm{p} 53$ oligomerisation domain lies at the extreme C-terminus (fig 3D); prematurely truncated forms cannot bind wild type and therefore do not act in a dominant negative fashion.

A possible example of Herskowitz's second class of dominant negative effect, involving a monomeric protein, is provided by certain point mutations in the RAS gene (fig 3A) ${ }^{6365} \mathrm{~A}$ mutant protein able to bind the guanine nucleotide exchange factor, but not be activated by it, will deplete the pool of this limiting factor available for activation of normal RAS.

Intriguingly, the dominant negative principle seems to have been exploited by certain naturally occurring regulatory systems, and representatives of both Herskowitz's classes are known. Belonging to the first class is the negative regulation, by formation of inactive heterodimers, of the transcription factors MyoD and c-Jun by the proteins Id and JunB respectively. Id is a truncated helix loop helix protein that forms dimers with MyoD, but lacks the adjacent basic region required for DNA binding. ${ }^{81}$ Similarly, critical amino acid substitutions in JunB abolish its homodimerisation and DNA binding, but favour formation of inactive JunB/c-Jun heterodimers.$^{82}$ In Herskowitz's second class is the interferon activator IRF1 and its antagonist IRF2; IRF2 has enhanced DNA binding and displaces IRF 1 from the interferon promoter, but is only weakly activating. ${ }^{83}$

\section{ALTERED STRUCTURAL PROTEINS}

At a simplistic level it is easy to understand why mutations of structural proteins are frequently dominant: admixture of normal and abnormal structural components will disrupt the integrity of the overall structure on a "weak links in a chain" principle. Careful cell biochemical analysis shows a more complex picture: additional modulators of the abnormal phenotype will include mRNA stability, and the degree of abnormality in cellular processing, secretion, and extracellular incorporation into mature fibrils, of the nascent protein. Mutations of type I collagen in osteogenesis imperfecta (OI) ${ }^{8485}$ and of fibrillin in Marfan syndrome ${ }^{8687}$ provide the best studied examples; in OI, there is a reasonable correlation between predicted disruption of structure caused by point mutations and exon skips and severity of phenotype. ${ }^{8485}$ By contrast, loss of function mutations have milder effects (see section on haploinsufficiency) ${ }^{27}$ Other structural proteins showing dominant mutations include myosin heavy chains (unc-54(d) mutations in $C$ elegans $^{88}$ and hypertrophic cardiomyopathy in humans ${ }^{89}$ ), and keratins 5 and 14 (Dowling-Meara epidermolysis bullosa). ${ }^{90}$ 
TOXIC PROTEIN ALTERATIONS

The common thread to these mutations, which are usually missense, is that they cause structural alterations in mono- or oligomeric proteins. These disrupt normal function and lead to toxic precursors or waste products from side reactions that poison the cell. Dominant negative effects are excluded. There are clear parallels with the mutational mechanisms in true structural proteins, but the phenotypic effects of toxic mutants are more unpredictable.

One commonplace example is the sickle mutation (haemoglobin S, $\beta 6 \mathrm{Glu} \rightarrow \mathrm{Val}$ ). (Although this shows largely recessive behaviour, coinheritance of a second mutation in cis (haemoglobin S Antilles, $\beta 23 \mathrm{Val} \rightarrow \mathrm{Ile}$ ) causes sickling to manifest in the heterozygote $\left.^{91}\right)$. Other examples include missense mutations of $C$ elegans degenerins, mec- 4 and deg-1, which cause specific neuronal cells to swell up, vacuolate, and lyse $\mathrm{e}^{92}$; a point mutation in mouse tyrosinase-related protein-1 (Light mutant) that disrupts melanosome structure $^{93}$; and various point mutations in rhodopsin associated with slow degeneration of rod photoreceptor outer segments. ${ }^{37} \mathrm{~A}$ particularly striking group comprises the dominantly inherited hereditary amyloidoses, a diverse collection of diseases associated with alterations in the structure of soluble proteins that increase stability of the protein and predispose to multimerisation. Proteins implicated include transthyretin, $\beta$ amyloid precursor protein, gelsolin, cystatin C, prion protein, apolipoprotein AI, lysozyme, and fibrinogen. ${ }^{94-96}$

\section{NEW PROTEIN FUNCTIONS}

The creation of new, advantageous protein functions by mutation is the life blood of evolution, but occurs over a protracted time scale. Proteins with truly new functions are only rarely encountered in natural human mutation and are usually pathological. Two categories may be recognised; missense mutations with specific functional effects, and assortative shuffling of exons. In protein engineering, which seeks to accelerate the evolutionary process and develop proteins with new functions, the same principles apply in the design of new mutants. ${ }^{97}$

The serine protease inhibitors (serpins), popular targets for protein engineering, provide perhaps the best natural example involving a missense mutation. A (358Met $\rightarrow$ Arg) substitution in $\alpha 1$ antitrypsin converts its activity to antithrombin, by altering the specificity of the active site. ${ }^{98}$ Another example, identified only in vitro, is a missense mutant protein (mev) that facilitates cellular uptake of mevalonate ${ }^{99}$; the wild type protein lacks this activity, but its normal function is unknown.

The juxtaposition of domains from different proteins to generate potentially new functions is best illustrated by the chimeric fusion proteins produced by some oncogenic chromosome translocations. ${ }^{5354}$ The c-ABL/BCR fusion products in the $9 ; 22$ Philadelphia translocation provide the most well characterised example, distinct chimeric fusion proteins being associated with chronic myeloid and acute lymphatic leukaemia. ${ }^{100}$ These proteins have a higher tyrosine kinase activity than normal c-ABL, and may also differ in substrate specificity. The PAX3 gene provides another example. Haploinsufficiency causes Waardenburg syndrome (see above), but translocation to a specific region of chromosome 13 is associated with alveolar rhabdomyosarcoma. ${ }^{101}$

\section{OTHER MECHANISMS OF DOMINANCE}

In this section are summarised briefly a variety of other more obscure, but nevertheless interesting mechanisms of dominance acting at a cellular level.

Position effect variegation in Drosophila is the variable reduction in expression of a gene juxtaposed to heterochromatin by chromosome rearrangement. Variegating mutations are generally recessive in that they reduce expression only from the rearranged (cis) chromosome. The brown locus is unusual in that expression is also reduced from the normal (trans) allele. This dominant effect seems to depend on somatic pairing between the homologous chromosomes, but the mechanisms of this and other 'trans sensing' effects are still uncertain. ${ }^{102103}$

The phenomenon of nucleolar dominance in wheat reflects the relative expression of tandem ribosomal DNA from allelic loci. Expression at an individual locus correlates with the number of upstream regulatory sequences. These appear to compete for binding to limiting amounts of an activating protein, so that the more repeats present, the greater the likelihood of activation. ${ }^{104}$

Segregation distortion loci subvert the normal pattern of 1:1 gametic segregation, leading to meiotic drive. This may occur either at meiosis, when some property of the general structure or size of a chromosome gives it a replication advantage on the spindle (chromosomal drive), or postmeiotically, when direct competition between the gametes occurs (genic drive). ${ }^{105}$ This may allow disadvantageous mutations to spread through the population, by virtue of close linkage to the drive locus. A well known example is the t complex of mouse.

Unlinked non-complementation occurs when heterozygous mutations occur at two genes coding for interacting proteins. Whereas the heterozygous state for either locus on its own is silent, concurrent mutations at both loci cause the phenotypic threshold to be exceeded, and the disease becomes manifest. Examples include the interaction of $\alpha$ and $\beta$ tubulin mutations in Drosophila ${ }^{106}$ and, more speculatively, the enhanced severity of dystrophin mutations in trans to an abnormal allele for autosomal recessive Fukuyama congenital muscular dystrophy. ${ }^{107}$

An allied phenomenon, called negative complementation or metabolic interference, occurs when two alleles at the same locus interact to give a more severe phenotype in the compound 
heterozygote than in either homozygote. For example, Abruptex (Abx) mutations of the Drosophila Notch gene fall into two genetic types, "enhancers" and "suppressors" of Notch. Homozygotes for either type are viable (characterised by gapping of the wing veins), yet compound enhancer/suppressor $\mathrm{Abx}$ heterozygotes are lethal..$^{767}$ Metabolic interference may theoretically result in various patterns of phenotypic segregation ${ }^{108}$ and has been invoked to explain the atypical inheritance of several human genetic diseases; none has yet been corroborated at the molecular level.

DOMINANT INHERITANCE, WITHOUT DOMINANCE AT A CELLULAR LEVEL

Although the vertical transmission of an abnormal character is usually assumed to imply dominance of the mutation at the cellular level, this is not always the case. In humans, two exceptions are sufficiently important to have been included in the table: recessive antioncogenes and imprinted loci.

Retinoblastoma provides the paradigmatic example of a phenotype that segregates in a dominant pattern, yet is the result of a mutation (in the RB1 gene) that is recessive at a cellular level. Cells carrying a heterozygous RB1 mutation are entirely normal, but a "second hit" somatic mutation of the normal allele in at least one retinal cell (a relatively likely event) causes retinoblastoma. ${ }^{109110}$ Analogous putative "antioncogenes" or "tumour suppressors" have been cloned in several other dominantly inherited cancer syndromes, including Li-Fraumeni syndrome (P53), neurofibromatosis types 1 and 2, familial adenomatous polyposis (APC), and Von Hippel-Lindau disease. At the cellular level, evidence for a purely recessive mechanism of gene action is, however, less certain than with RB1, and varying contributions from haploinsufficient and dominant negative effects are possible, as discussed for P53 and APC.

Genomic imprinting may give rise to a complex pattern of dominant inheritance. If a gene is transcribed only from the chromosome originating from one of the two parents, the locus is effectively hemizygous. Mutation of the allele on the 'active' chromosome will completely inactivate the locus, whereas mutation of the allele on the other chromosome will have no phenotypic effect. Apparent dominant transmission of the disorder can occur, but this will show dependence on the sex of the transmitting parent. Representative pedigrees are provided by transgenic mutation of the mouse insulin-like growth factor-II gene, ${ }^{111}$ and in the human diseases Beckwith-Wiedemann syndrome $e^{112}$ and hereditary paraganglioma. ${ }^{113}$

\section{Perspectives on human genetic disease}

Although this classification may initially appear to be an academic exercise, appreciation of these various mechanisms is helpful for thinking about disease processes. For example, perusal of the table and fig 3 indicates that a different mutational spectrum may be anticipated in different diseases, according to their cellular mechanism. A wide variety of mutations cause loss of function: disease genes with a high mutation rate will often be haploinsufficient and be involved in regulatory pathways or act as tumour suppressors or both. A search for constitutional chromosomal abnormalities (deletions, translocations), which provide such an invaluable resource for disease location and positional cloning, ${ }^{114}$ is much more likely to be successful in this group than in the "gain of function" categories. By contrast, acquired chromosomal abnormalities in neoplasia may often pinpoint specific oncogenes involved in "gain of function" transformation. The phenotype associated with missense mutations will usually be critically dependent on their exact position and nature, except in structural proteins; hence multiple, independent point mutations as a cause of dominant disease are most commonly encountered in such proteins.

In understanding mechanisms of cancer, the dominant negative effects illustrated for $\mathrm{p} 53$ may occur in other tumour suppressor genes. For instance, germline mutations of the APC gene cause familial adenomatous polyposis/ Gardner's syndrome, and somatic mutations occur in sporadic colon cancer. The amino acid sequence of APC predicts that it will form coiled coils, structural elements that permit oligomerisation. ${ }^{15116}$ The majority of APC mutants, both germline and somatic, are missense $^{117118}$ and some could disrupt normal oligomers to give dominant negative effects. Analysis of the particular mutations present may therefore guide prognosis.

The mechanisms of dominance in conditions associated with unstable triplet repeats (for example, fragile $\mathrm{X}$ syndrome, myotonic dystrophy, and Huntington's disease) are not yet clear, and probably heterogeneous, with effects owing to alterations in both mRNA expression and protein function. Although the (CGG) ${ }_{n}$ expansion in the fragile $\mathrm{X}$ syndrome is associated with DNA methylation and absence of FMR-1 gene expression, ${ }^{119}$ in myotonic dystrophy, DMK alleles containing (CTG) expansions may actually be overexpressed ${ }^{120}$ (although this is disputed ${ }^{121122}$ ). Other potential variables are whether the expanded triplet lies in the coding or non-coding region of the protein, and the sequence of the repeat itself. ${ }^{123}$ Complete elucidation of the mechanisms of dominance associated with triplet repeat expansion may well yield some surprises.

Finally, an understanding of the molecular mechanism of a disease is a prerequisite for attempting gene therapy. Nearly all diseases currently targeted for gene therapy are recessive, ${ }^{124}$ in which the goal is simply to replace the missing product. It should be evident that most categories of dominant disease pose a formidable challenge to gene therapy, but already the "molecular engineers" are contemplating strategies to overcome these problems. Examples include antisense RNA therapy to antagonise selectively the action of dominant negative mutants; or conversely, the introduction of such mutants to counteract the effects 
of increased mRNA expression or protein activity.

The idea for this review originated from a meeting of the Genetical Society (Dominance and recessiveness revisited", Edinburgh, 25 September 1992). I am very grateful to the organiser, Veronica van Heyningen, and all contributing speakers for putting togeth Higgs, Peter Harper, William Reardon, Sarah Slaney, and an anonymous referee made helpful comments on the manuscript.

1 Bennett $\mathrm{JH}$, ed. Experiments in plant hybridisation by $G$ Mendel. London: Oliver \& Boyd, 1965.

2 Vogel F, Motulsky AG. Human genetics: problems and approaches. 2nd ed. Berlin: Springer Verlag, 1986:228333.

3 Jackson IJ. Mouse coat colour mutations: a molecula enetic resource which spans the centuries. Bioessays 1991:13:439-46.

4 Pauli RM, Conroy MM, Langer LO, et al. Homozygous achondroplasia with survival beyond infancy. $A m \mathcal{F} \mathrm{Med}$ Genet 1983;16:459-73.

5 Hultén MA, Honeyman MM, Mayne AJ, Tarlow MJ. Homozygosity in piebald trait. $\mathcal{f}$ Med Gene 1987;24:568-71.

6 Pauli RM. Dominance and homozygosity in man. Am Med Genet 1983;16:455-8.

7 Wexler NS, Young AB, Tanzi RE, et al. Homozygotes fo Huntington's disease. Nature 1987;326:194-7.

8 Myers RH, Leavitt J, Farrer LA, et al. Homozygote fo Huntington disease. Am $\mathcal{F}$ Hum Genet 1989;45:615-8.

9 The Huntington's Disease Collaborative Research Group. A novel gene containing a trinucleotide repeat that is expanded and unstable on Huntington's disease chromosomes. Cell 1993;72:971-83.

10 McKusick VA. Mendelian inheritance in man: catalogs of autosomal dominant, autosomal recessive, and phenotypes. 10th ed.

11 Vogel F, Motulsky AG. Human genetics: problems and approaches. 2nd ed. Berlin: Springer Verlag, 1986:128-9.

12 Jaenisch R. Transgenic animals. Science 1988;240:1468-74.

3 Friedrich G, Soriano P. Promoter traps in embryonic stem cells: a genetic screen to identify and mutate developcells: a genetic screen to identify and mutate de
mental genes in mice. Genes Dev 1991;5:1513-23.

14 Orr HA. A test of Fisher's theory of dominance. Proc Natl Acad Sci USA 1991;88:11413-5.

15 Charlesworth B. When to be diploid. Nature 1991;351:273 4.

16 Kondrashov AS, Crow JF. Haploidy or diploidy: which is better? Nature 1991;351:314-5.

17 Perrot V, Richerd S, Valéro $M$. Transition from haploidy to diploidy. Nature 1991;351:315-7.

$18 \mathrm{Kacser} \mathrm{H}$, Burns JA. The molecular basis of dominance. Genetics 1981;97:639-66.

19 Hodgkin J, Papp A, Pulak R, Ambros V, Anderson P. A new kind of informational suppression in the nematod Caenorhabditis elegans. Genetics 1989;123:301-13.

20 Hodgkin J. Fluxes, doses and poisons: molecular perspectives on dominance. Trends Genet 1993;9:1-2.

$21 \mathrm{Li}$ E, Sucov HM, Lee KF, Evans RM, Jaenisch R. Norma development and growth of mice carrying a targeted disruption of the $\alpha 1$ retinoic acid receptor gene. Proc Natl Acad Sci USA 1993;90:1590-4.

22 Park EC, Horvitz HR. Mutations with dominant effects on the behavior and morphology of the nematode Caenorhabditis elegans. Genetics 1986;113:821-52.

23 Muller HJ. Further studies on the nature and causes of gene mutations. In: Jones DF, ed. Proceedings of the sixth Froklyn Botanic Sixth dens, Wisconsin, 1932:213-55.

24 Carlson EA. Defining the gene: an evolving concept. $A m \mathcal{F}$ Hum Genet 1991;49:475-87.

25 Lindsley DL, Sandler L, Baker BS, et al. Segmental aneuploidy and the genetic gross structure of the Drosophila ploidy and the genetic gross structur

26 Ingham P, Smith J. Crossing the threshold. Curr Biol 1992;2:465-7.

27 Willing MC, Pruchno CJ, Atkinson M, Byers PH. Osteogenesis imperfecta type I is commonly due to a COL $1 \mathrm{Al}$ null allele of

28 Goldstein JL, Sobhani MK, Faust JR, Brown MS. Heterozygous familial hypercholesterolemia: failure of norma allele to compensate for mutant allele at a regulated genetic locus. Cell 1976;9:195-203.

29 Lachmann PJ, Rosen FS. The catabolism of C1-inhibito and the pathogenesis of hereditary angio-edema. Acta Pathol Microbiol Immunol Scand 1984;92 (Sect C, supp 284):35-9.

30 Tassabehji $M$, Read AP, Newton VE, et al. Mutations in the $P A X 3$ gene causing Waardenburg syndrome type and type 2. Nature Genet 1993;3:26-30

31 Gruss P, Walther C. Pax in development. Cell 1992;69:71922.

32 Glaser T, Walton DS, Maas RL. Genomic structure, evolutionary conservation and aniridia mutations in the human $P A X 6$ gene. Nature Genet 1992;2:232-8.

33 Vortkamp A, Gessler M, Grzeschik KH. GLI3 zinc-finger gene interrupted by translocations in Greig syndrome families. Nature 1991;352:539-40.

34 Schimmang $T$, Lemaistre $M$, Vortkamp A, Rüther $U$.
Expression of the zinc finger gene Gli3 is affected in the morphogenetic mouse mutant extra-toes $(X t)$. Development 1992;116:799-804.

35 Hastie ND. Dominant negative mutations in the Wilms tumour (WT1) gene cause Denys-Drash syndrome proof that a tumour-suppressor gene plays a crucial role in normal genitourinary development. Hum Mol Genet 1992;1:293-5.

36 Little MH, Williamson KA, Mannens M, et al. Evidence that WT1 mutations in Denys-Drash syndrome patients may act in a dominant negative fashion. Hum Mol Genet 1993;2:259-64.

37 McInnes RR, Bascom RA. Retinal genetics: a nullifying effect for rhodopsin. Nature Genet 1992;1:155-7.

38 Spritz RA, Holmes SA, Ramesar R, Greenberg J, Curtis D, Beighton P. Mutations of the KIT (mast/stem cell growth factor receptor) proto-oncogene account for a continuous range of phenotypes in human piebaldism. Am $\mathcal{f}$ Hum Genet 1992;51:1058-65.

39 Younger-Shepherd S, Vaessin H, Bier E, Jan LY, Jan YN. deadpan, an essential pan-neural gene encoding an HLH protein, acts as a denominator in

40 Isoda K, Roth S, Nüsslein-Volhard C. The functional domains of the Drosophila morphogen dorsal: evidence from the analysis of mutants. Genes Dev 1992;6:619-30.

41 Jiang J, Levine $M$. Binding affinities and cooperative interactions with bHLH activators delimit threshold responses to the dorsal gradient morphogen. Cell 1993;72:741-52.

42 St Johnston D, Nüsslein-Volhard C. The origin of pattern and polarity in the Drosophila embryo. Cell 1992;68:201-19.

43 Holtzman DM, Epstein CJ. The molecular genetics of Down syndrome. Mol Genet Med 1992;2:105-20.

44 Patel PI, Roa BB, Welcher AA, et al. The gene for the peripheral myelin protein PMP-22 is a candidate for Charcot-Marie-Tooth disease type 1A. Nature Genet 1992;1:159-65.

45 Chance PF, Alderson MK, Leppig KA, et al. DNA deletion associated with hereditary neuropathy with liability to pressure palsies. Cell 1993;72:143-51.

46 Bishop JM. Molecular themes in oncogenesis. Cell 1991;64:235-48.

47 Oliner JD, Kinzler KW, Meltzer PS, George DL, Vogelstein B. Amplification of a gene encoding a p53-associstein B. Amplification of a gene encoding a p53-associ-

48 Ruvkun G, Wightman B, Burglin T, Arasu P. Dominant gain-of-function mutations that lead to misregulation of gain-of-function mutations that lead to misregulation of the $C$ elegans heterochronic gene lin-14, and the evolutionary implications of dominant mutations in

49 Martin DIK, Tsai SF, Orkin SH. Increased $\gamma$-globin expression in a nondeletion HPFH mediated by an erythroid-specific DNA-binding factor. Nature 1989;338:435-8.

50 Feingold EA, Forget BG. The breakpoint of a large deletion causing hereditary persistence of fetal hemoglobin occurs within an erythroid DNA domain remote from the $\beta$ globin gene cluster. Blood 1989;74:2178-86.

51 White RAH, Akam ME. Contrabithorax mutations cause inappropriate expression of Ultrabithorax products in Drosophila. Nature 1985;318:567-9.

52 Schneuwly S, Kuroiwa A, Gehring WJ. Molecular analysis of the dominant homeotic Antennapedia phenotype. $E M B O$ f 1987;6:201-6.

53 Cleary ML. Oncogenic conversion of transcription factors by chromosomal translocations. Cell 1991;66:619-22.

54 Rabbitts TH. Translocations, master genes, and differences between the origins of acute and chronic leukemias. Cell $1991 ; 67: 641-4$

55 Trent C, Wood WB, Horvitz HR. A novel dominant transformer allele of the sex-determining gene her-1 of Caenorhabditis elegans. Genetics 1988;120:145-57.

56 Miller MW, Duhl DMJ, Vrieling H, et al. Cloning of the mouse agouti gene predicts a secreted protein ubiquimouse agouti gene predicts a secreted protein ubiquitously expressed in mice carrying

57 Michaud EJ, Bultman SJ, Stubbs LJ, Woychik RP. The embryonic lethality of homozygous lethal yellow mice $\left(A^{y} / A^{y}\right)$ is associated with the disruption of a novel RNAbinding protein. Genes Dev 1993;7:1203-13.

58 Bruening W, Bardeesy N, Silverman BL, et al. Germline intronic and exonic mutations in the Wilms' tumour gene (WT1) affecting urogenital development. Nature Genet 1992;1:144-8

59 Bickmore WA, Oghene $\mathrm{K}$, Little $\mathrm{MH}$, Seawright A, van Heyningen V, Hastie ND. Modulation of DNA bindin specificity by alternative splicing of the Wilms tumor wt $I$ gene transcript. Science 1992;257:235-7.

60 Rogers S, Wells R, Rechsteiner M. Amino acid sequences common to rapidly degraded proteins: the PEST hypothesis. Science 1986;234:364-8.

61 Reed SI. G1-specific cyclins: in search of an S-phasepromoting factor. Trends Genet 1991;7:95-9.

62 Mango SE, Maine EM, Kimble J. Carboxy-terminal truncation activates $g l p-1$ protein to specify vulval fates in Caenorhabditis elegans. Nature 1991;352:811-5.

63 Bourne HR, Sanders DA, McCormick F. The GTPase superfamily: conserved structure and molecular mechanism. Nature 1991;349:117-27.

64 Beitel G, Clark S, Horvitz HR. The Caenorhabditis elegan ras gene let-60 acts as a switch in the pathway of vulval induction. Nature 1990;348:503-9.

65 Han $M$, Sternberg PW. Analysis of dominant-negative 
mutations of the Caenorhabditis elegans let-60 ras gene. Genes Dev 1991;5:2188-98.

66 Schneider DS, Hudson KL, Lin TY, Anderson KV. Dominant and recessive mutations define functional domains of Toll, a transmembrane protein required for dorsalventral polarity in the Drosophila embryo. Genes Dev 1991;5:797-807.

67 Vogelstein B. A deadly inheritance. Nature 1990;348:681-2.

68 Vogelstein B, Kinzler KW. p53 function and dysfunction. Cell 1992:70:523-6.

69 Milner J, Medcalf EA. Cotranslation of activated mutant p53 with wild type drives the wild-type p53 protein into p53 with wild type drives the wild-type p53 pro

70 Weinstein LS, Shenker A, Gejman PV, Merino MJ, Friedman E, Spiegel AM. Activating mutations of the stimulaman E, Spiegel AM. Activating mutations of the stimulatory $G$ protein in the McCun

71 Schwindinger WF, Francomano CA, Levine MA. Identification of a mutation in the gene encoding the $\alpha$ subunit of
the stimulatory $G$ protein of adenylyl cyclase in the stimulatory $G$ protein of adenylyl cyclase in McCune-Albrig

72 Ptácek LJ, George AL, Griggs RC, et al. Identification of a mutation in the gene causing hyperkalemic periodic paralysis. Cell 1991;67:1021-7.

73 Rojas CV, Wang J, Schwartz LS, Hoffman EP, Powell BR, Brown RH Jr. A Met-to-Val mutation in the skeletal muscle $\mathrm{Na}^{+}$channel $\alpha$-subunit in hyperkalaemic periodic paralysis. Nature 1991;354:387-9.

74 McClatchey AI, Van den Bergh P, Pericak-Vance MA, al. Temperature-sensitive mutations in the III-IV cytoplasmic loop region of the skeletal muscle sodium channel gene in paramyotonia congenita. Cell 1992;68:769-74.

75 Valentijn LJ, Baas F, Wolterman RA, et al. Identical point mutations of $P M P-22$ in Trembler-f mouse and CharcotMarie-Tooth disease type 1A. Nature Genet 1992;2:28891.

76 Kelley MR, Kidd S, Deutsch WA, Young MW. Mutations altering the structure of epidermal growth factor-like coding sequences at the Drosophila Notch locus. Cell 1987;51:539-48.

77 Xu T, Rebay I, Fleming RJ, Scottgale TN, ArtavanisTsakonas S. The Notch locus and the genetic circuitry involved in early Drosophila neurogenesis. Genes Dev involved in early

78 Herskowitz I. Functional inactivation of genes by dominant 1987;329:219-22.

79 Amaya E, Musci TJ, Kirschner MW. Expression of a dominant negative mutant of the FGF receptor disrupts mesoderm formation in Xenopus embryos. Cell 1991;66:257-70.

80 Leone G, Maybaum L, Lee PWK. The reovirus cell attachment protein possesses two independently active trimerization domains: basis of dominant negative effects. Cell 1992;71:479-88.

81 Benezra R, Davis RL, Lockshon D, Turner DL, Weintraub $H$. The protein Id: a negative regulator of helix-loophelix DNA binding proteins. Cell 1990;61:49-59.

82 Deng $T$, Karin $M$. JunB differs from c-Jun in its DNAbinding and dimerization domains, and represses c-Jun by formation of inactive heterodimers. Genes Dev 1993;7:479-90.

83 Harada $H$, Fujita $T$, Miyamoto $M$, et al. Structurally similar but functionally distinct factors, IRF-1 and IRF2 , bind to the same regulatory elements of IFN and IFNinducible genes. Cell 1989;58:729-39.

84 Sykes B. Bone disease cracks genetics. Nature 1990;348:18-

85 Byers PH, Wallis GA, Willing MC. Osteogenesis imperfecta: translation of mutation to phenotype. $\mathcal{F}$ Med Genet 1991;28:433-42.

86 Dietz HC, Cutting GR, Pyeritz RE, et al. Marfan syndrome caused by a recurrent de novo missense mutation in the caused by a recurrent de novo missen
fibrillin gene. Nature 1991;352:337-9.

87 Milewicz DMcG, Pyeritz RE, Crawford ES, Byers PH. Marfan syndrome: defective synthesis, secretion, and Marfan syndrome: defective synthesis, secretion, and extracellular matrix formation of fibrilin by

88 Beisovec A, Anderson P. Functions of the myosin ATP and actin binding sites are required for $\mathrm{C}$ elegans thick filament assembly. Cell 1990;60:133-40.

89 Watkins H, Rosenzweig A, Hwang DS, et al. Characteristics and prognostic implications of myosin missense mutations in familial hypertrophic cardiomyopathy. $N$ Engl f Med 1992;326:1 108-14.

90 Fuchs E, Coulombe PA. Of mice and men: genetic skin diseases of keratin. Cell 1992;69:899-902.

91 Monplaisir N, Merault G, Poyart C, et al. Hemoglobin S Antilles: a variant with lower solubility than hemoglobin $\mathrm{S}$ and producing sickle cell disease in heterozygotes. Proc Natl Acad Sci USA 1986;83:9363-7.

92 Driscoll M, Chalfie M. The mec-4 gene is a member of a family of Caenorhabditis elegans genes that can mutate to induce neuronal degeneration. Nature 1991;349:588-93.

93 Johnson R, Jackson IJ. Light is a dominant mouse mutation resulting in premature cell death. Nature Genet 1992;1:226-9.

94 Citron M, Oltersdorf T, Haass C, et al. Mutation of the $\beta$ - amyloid precursor protein in familial Alzheimer's disease increases $\beta$-protein production. Nature 1992;360:672-4. 95 Benson MD, Liepnieks J, Uemichi T, Wheeler G, Correa R. Hereditary renal amyloidosis associated with a mutan fibrinogen $\alpha$-chain. Nature Genet 1993;3:252-5.

96 Pepys MB, Hawkins PN, Booth DR, et al. Human lysozyme gene mutations cause hereditary systemic amyloidosis. Nature 1993;362:553-7.

97 Fersht A, Winter G. Protein engineering. Trends Biochem Sci 1992;17:292-4.

98 Owen MC, Brennan SO, Lewis JH, Carrell RW. Mutation of antitrypsin to antithrombin. $\alpha 1$-antitrypsin Pittsburgh (358 Met $\rightarrow$ Arg), a fatal bleeding disorder. $N$ Engl f Med 1983;309:694-8.

99 Kim CM, Goldstein JL, Brown MS. cDNA cloning of MEV, a mutant protein that facilitates cellular uptake of mevalonate, and identification of the point mutation mevalonate, and identification of the point mutation responsible for its

100 Kurzrock R, Gutterman JU, Talpaz M. The molecular genetics of Philadelphia chromosome-positive leukemias. $N$ Engl f Med 1988;319:990-8.

101 Barr FG, Galili N, Holick J, Biegel JA, Rovera G, Emanuel BS. Rearrangement of the PAX 3 paired box gene in the paediatric solid tumour alveolar rhabdomyosarcoma. Nature Genet 1993;3:113-7.

102 Dreesen TD, Henikoff S, Loughney K. A pairing-sensitive element that mediates trans-inactivation is associated with the Drosophila brown gene. Genes Dev 1991;5:33140.

103 Tartof KD, Henikoff S. Trans-sensing effects from Drosophila to humans. Cell 1991;65:201-3.

104 Flavell RB. Variation in structure and expression of ribosomal DNA loci in wheat. Genome 1989;31:963-8.

105 Lyttle TW. Cheaters sometimes prosper: distortion of mendelian segregation by meiotic drive. Trends Genet 1993;9:205-10.

106 Hays TS, Deuring R, Robertson B, Prout M, Fuller MT. Interacting proteins identified by genetic interactions: a missense mutation in $\alpha$-tubulin fails to complement alleles of the testis-specific $\beta$-tubulin gene of Drosophila melanogaster. Mol Cell Biol 1989;9:875-884.

107 Beggs AH, Neumann PE, Arahata K, et al. Possible influences on the expression of $\mathrm{X}$, et al. Possible dystrophin abnormalities by heterozygosity for autosodystrophin abnormalities by heterozygosity for autosomal recessive Fukuyama congenital muscu
Proc Natl Acad Sci USA 1992;89:623-7.

108 Johnson WG. Metabolic interference and the +- heterozygote. A hypothetical form of simple inheritance which is neither dominant nor recessive. Am $\mathcal{f}$ Hum Genet 1980;32:374-86.

109 Knudson AG. Mutation and cancer: statistical study of retinoblastoma. Proc Natl Acad Aci USA 1971;68:820-3.

110 Cavenee WK, Dryja TP, Phillips RA, et al. Expression of recessive alleles by chromosomal mechanisms in retinoblastoma. Nature 1983;305:779-84.

111 DeChiara TM, Robertson EJ, Efstratiadis A. Parental imprinting of the mouse insulin-like growth factor II gene. Cell 1991;64:849-59.

112 Koufos A, Grundy P, Morgan K, et al. Familial Wiedemann-Beckwith syndrome and a second Wilms tumor locus both map to $11 \mathrm{p} 15.5$. Am $\mathcal{f}$ Hum Genet 1989;44:711-19.

113 Heutink P, van der Mey AGL, Sandkuijl LA, et al. A gene subject to genomic imprinting and responsible for hereditary parangliomas maps to chromosome 11q23-qter. Hum Mol Genet 1992;1:7-10.

114 Tommerup N. Mendelian cytogenetics. Chromosome rearrangements associated with mendelian disorders. $f$ Med Genet 1993;30:713-27.

115 Bourne HR. Consider the coiled coil . . Nature 1991;351:188-90.

116 Bourne HR. Suppression with a difference. Nature 1991;353:696-8.

117 Miyoshi Y, Ando H, Nagase H, et al. Germ-line mutations of the $A P C$ gene in 53 familial adenomatous polyposis of the APC gene in 5 familial adenomatous polyposis

118 Powell SM, Zilz N, Beazer-Barclay Y, et al. APC mutations occur early during colorectal tumorigenesis. Nature 1992;359:235-7.

119 Pieretti M, Zhang F, Fu YH, et al. Absence of expression of the FMR-1 gene in fragile $\mathrm{X}$ syndrome. Cell $1991 ; 66: 817-22$.

120 Sabouri LA, Mahadevan MS, Narang M, Lee DSC, Surh LC, Korneluk RG. Effect of the myotonic dystrophy (DM) mutation on mRNA levels of the DM gene. Nature Genet 1993;4:233-8

$121 \mathrm{Fu} \mathrm{YH}$, Friedman DL, Richards $S$, et al. Decreased expression of myotonin-protein kinase messenger RNA and protein in adult form of myotonic dystrophy. Science 1993;260:235-8.

122 Hofmann-Radvanyi H, Lavedan C, Rabès JP, et al. Myotonic dystrophy: absence of CTG enlarged transcript in congenital forms, and low expression of the normal allele. Hum Mol Genet 1993;2:1263-6.

123 Mandel JL. Questions of expansion. Nature Genet 1993;4:8-9.

124 Miller AD. Human gene therapy comes of age. Nature 1992;357:455-60. 